\title{
Reconstrucción exclusionaria. Lo comunitario y las políticas públicas en ciudades menores e intermedias chilenas afectadas por el terremoto y tsunami del 27 F2010. Los casos de Constitución y Dichato ${ }^{1}$
}

\author{
Yasna Contreras Gatica ${ }^{2}$ y Carolina Arriagada Sickinger ${ }^{3}$
}

\begin{abstract}
RESUMEN
La reconstrucción en ciudades menores e intermedias chilenas afectadas por el terremoto y tsunami del 27 de febrero de 2010 exige cuestionarse cuál es la capacidad de articulación entre agentes públicos, privados y comunidad para enfrentar la reconstrucción postdesastre. También es pertinente preguntarse si la gentrificación es un proceso latente dada la reconfiguración sociourbana de Dichato y Constitución, así como también las modalidades de desplazamiento, radicación y relocalización de la población afectada. Constitución y Dichato como espacios intermedios ayudan a regionalizar y vincular el estudio de la gentrificación en escenaríos de reconstrucción más allá de las grandes ciudades capitalistas. Metodológicamente se recurre a encuestas, entrevistas a residentes afectados, así como agentes públicos y privados. Para identificar los mecanismos de articulación entre agentes territoriales se estudian seis dimensiones: reconstrucción del medio construido; reconstrucción sicológica, mecanismos de gestión del riesgo, sistema económico, estructura política y capital social antes y después del desastre.
\end{abstract}

Palabras clave: Reconstrucción, gentrificación, exclusión y capitalización del desastre

\begin{abstract}
Reconstruction in small and medium-sized Chilean cities that were affected by the earthquake and tsunami on February 27th 2010, calls in to the question the capacity for coordination between public and private agents and the community to face the reconstruction post disaster. It is also relevant to wonder if gentrification is a latent process of the urban and social reconfiguration of Dichato and Constitución as well as patterns of displacement, establishment and relocation of the affected population. The cases of Constitución and Dichato help to link the study of gentrification in reconstruction locations beyond the big capitalist cities.
\end{abstract}

1 Artículo recibido el 23 de diciembre de 2016, aceptado el 17 de mayo de 2016 y corregido el 28 de junio de 2016.

2 Departamento de Geografía, Universidad de Chile (Chile). E-mail: ycontrerasg@uchilefau.cl

\footnotetext{
Departamento de Planificación y Diseño Urbano, Universidad del Biobío (Chile).

E-mail: carriagada@ubiobio.cl
} 


\begin{abstract}
Methodologically, data was based on surveys, interviews affected residents, as well as public and private agents. To identify mechanisms of coordination between territorial agents six dimensions were studied: reconstruction of built environment; psychological reconstruction, mechanisms of risk management, economic system, political structure and social capital prior to and after the disaster.
\end{abstract}

Key words: Reconstruction, gentrification, exclusion, disaster capitalization

El proceso de reconstrucción en las ciudades intermedias y menores chilenas afectadas por el terremoto y posteríor tsunami del 27 de febrero del 2010 -de aquí en adelante $27 \mathrm{~F}-$, plantean diferentes interrogantes en cuanto a la capacidad de reconstrucción de los espacios afectados, o la articulación entre la comunidad y agentes públicos y privados, así como también se cuestiona si la gentrificación es un proceso latente dadas las diferentes modalidades de desplazamientos, relocalización y cambios normativos inciertos. Dos son los casos aquí explorados: la ciudad intermedia Constitución con casi 55 mil habitantes (INE, 2012) localizada a más de $300 \mathrm{~km}$ de la capital de Chile. En segundo lugar, se analiza el proceso en la localidad de Dichato que concentra casi 4 mil habitantes, ubicándose a más de $500 \mathrm{~km}$ de la ciudad de Santiago (INE, 2012).

Se parte del supuesto de una desarticulación entre agentes públicos, privados y la comunidad para enfrentar el proceso. Lo anteríor, sustentado además, en una planificación territorial centralizada en Santiago no solo en términos de recursos para enfrentar los desastres, también desde una dimensión política. Asimismo, la capacidad de articulación entre agentes territoriales responde a una planificación territorial que no aborda el riesgo en su complejidad ni en su recursividad.

En el artículo se postula la gentrificación latente en ciudades intermedias y menores, sin embargo con diferencias a los estudios clásicos de la gentrificación dada la condición de desastre a la que se vieron sometidos tanto Constitución como Dichato. En primer lugar, la latencia del proceso está vinculada a los mecanismos de desplazamiento, relocalización, radicación y erradicación de la población. En segundo lugar, las incertezas normativas en ambos espacios Ileva a sustentar la tesis de especulación inmobiliaria y comercial, en tanto en ambos sitios se han y se es- tán construyendo proyectos significativos que plantean la tesis de una reconfiguración urbana, entre estos el Parque de Mitigación en Constitución, la recuperación de la costanera Pedro Aguirre Cerda y el estero en Dichato. En tercer lugar, existen paños disponibles en torno al borde mar y río, las que aún no están determinadas dados los actuales estudios de los Planes Reguladores Comunales. Por tanto, se entiende que la reconstrucción es exclusionaria, en tanto la articulación de agentes privados y públicos versa sobre un urbanismo pro empresarial (Harvey, 2008).

La metodología de investigación combina datos cuantitativos y cualitativos a objeto de discutir los efectos del proceso de reconstrucción en dos espacios con diferentes escalas y con diversas formas de articulación entre agentes territoriales. A partir de entrevistas en profundidad se analiza el papel de los gobiernos centrales, regionales y locales asumiendo a príori, que su condición de centros urbanos inferíores en una jerarquía urbana centralizada, limita aún más su poder de gestión institucional no solo en la fase de emergencia, también durante la reconstrucción postdesastre.

La discusión se plantea en cuatro apartados. En el primero se explica la metodología cualitativa y cuantitativa de investigación. El segundo tiene una orientación teórica que articula los conceptos reconstrucción, exclusión, gentrificación y capitalización del desastre. En una tercera parte se dan respuesta a las preguntas que guían la discusión en función de dos casos de estudios. Se analizan los efectos de la reconstrucción postdesastre. Se indagan sobre los niveles de articulación de agentes públicos, privados y comunidad durante las fases de emergencia y reconstrucción, así como también los diferentes tipos de desplazamientos y relocalización en el marco de la reconstrucción. Conjuntamente se cuestiona el grado de reconfiguración 
socioespacial postdesastre considerando los instrumentos de planificación existentes en las dos ciudades, y los grados de avance en términos de articulación entre agentes territoriales. De forma complementaria, se analiza en qué medida la gobernanza en núcleos urbanos menores y en ciudades intermedias conduciría hacia procesos de reconstrucción de largo plazo, bajo principios de sustentabilidad y equidad. Si bien el artículo buscó cuestionar la gobernanza como eje central de discusión se consideró abarcar sus dimensiones en los casos de estudio, con el propósito de hacer propuestas que permitan avanzar hacia una resiliencia sustentable en espacios de desastre.

\section{Metodología de investigación}

Se privilegian los análisis cualitativos logrados a través de entrevistas en profundidad aplicadas a diferentes personas y a actores públicos y privados que lideraron el proceso desde la fase de emergencia o impacto hasta el actual proceso de reconstrucción. En la Figura $N^{\circ} 1$ se delimitan las dos áreas urbanas afectadas por el tsunami, graficando la cota real de inundación durante el 27F. Comparar dos casos de estudios permite evaluar y analizar los mecanismos de reconstrucción postdesastre en una estructura territorial fuertemente centralizada, donde el riesgo comprende una zonificación dentro de normas urbanas, pero no es asumida en la complejidad del término. Indistintamente la talla demográfica, el análisis de las normativas urbanas y los discursos de sus residentes permiten evaluar el grado de relaciones de estos espacios y la temporalidad de las acciones en el marco de la reconstrucción.

Los resultados responden a dos fuentes de investigación: en el caso de Constitución el análisis se nutre de información capturada desde el año 2011 al 2014 así como también, incluye 15 entrevistas en profundidad aplicadas durante el 2014. Se efectuaron 5 entrevistas en la zona de mayor desastre en Constitución, específicamente el sector La Poza. Conjuntamente, se aplicaron 10 entrevistas en los espacios que acogieron residentes relocalizados: Cerro Centinella, Quinta Gaete y Villa Los Verdes (Figura $N^{\circ} 1$ ). Como agentes claves de la reconstrucción se entrevistaron a Celulosa Arauco (CELCO), inmobiliarias y constructoras encargadas de la reconstrucción, bomberos, Fuerzas Armadas, Municipio de Constitución y Servicio de Vivienda y Urbanización (SERVIU).

En Dichato los datos resultan de una investigación realizada entre los años 2014 a 2015. Se aplicaron 22 entrevistas en profundidad a actores relevantes tanto de la comunidad afectada, como representantes del gobierno local y regional. Las entrevistas y el trabajo de campo se orientaron en indagar los mecanismos de articulación entre actores públicos, privados y la comunidad, así como también, responder en qué medida la gentrificación era un proceso latente. Cuantitativamente se espacializaron datos derivados de los patrones de densidad en ambos espacios, a objeto de comprender el sentido de los desplazamientos y los efectos en cuanto al poder de negociación de los sujetos afectados durante la fase postdesastre.

Luego de analizadas las entrevistas con actores públicos y privados se construyó una matriz calificada en base a la metodología aplicada por Comerío (2014), estructurada en seis dimensiones expuestas en el cuadro 1: reconstrucción del medio construido, reconstrucción sicológica, gestión del riesgo, sistema económico, estructura política y capital social. Esta metodología incorporó diferentes variables cuantificadas a partir de los mecanismos de reconstrucción que operan en los espacios de análisis, identificándose el total de viviendas relocalizadas fuera de las zonas de riesgos, las viviendas construidas en sitio propio, la red de infraestructura existente y construida luego del desastre, la localización de centrales de telecomunicación y equipamientos en espacios seguros. La dimensión sicológica del desastre se analizó en función de la revisión de documentos en centros de salud; la aplicación de las entrevistas, así como también, las formas de educar el riesgo en las escuelas de ambas ciudades. Cada una de las variables fue calificada de 1 a 7 considerando el análisis de las entrevistas y la calificación asignada por cada organismo público, privado y comunidad entrevistada. Se recurre a la gobernanza resiliente no como elemento central de la discusión, sino más bien como estrategia que debiera liderar los procesos de reconstrucción en Chile, indistintamente el tipo de desastre o la escala que este afecte. 
Cuadro $\mathrm{N}^{\circ} 1$

Variables para la medición de la gobernanza del desastre y reconstrucción

\begin{tabular}{|c|c|}
\hline Dimensión & Variables \\
\hline \multirow{8}{*}{$\begin{array}{l}\text { Reconstrucción del me- } \\
\text { dio construido }\end{array}$} & Viviendas relocalizadas fueras de zonas de riesgos \\
\hline & Viviendas en sitio propio con medidas de mitigación \\
\hline & Red secundaria infraestructura sanitaria \\
\hline & Vías secundarias \\
\hline & Localización de centrales de telecomunicación en zonas seguras \\
\hline & Espacios públicos en zonas seguras \\
\hline & Equipamientos en zonas seguras \\
\hline & Parque de mitigación \\
\hline $\begin{array}{l}\text { Reconstrucción } \\
\text { sicológica }\end{array}$ & Proceso psicosocial postrauma \\
\hline \multirow{2}{*}{ Gestión del riesgo } & Educación del riesgo \\
\hline & Modificación del plan regulador \\
\hline \multirow{2}{*}{ Sistema económico } & Nuevas ofertas laborales \\
\hline & Subsidios de apoyo al comercio local \\
\hline \multirow{4}{*}{ Estructura política } & Articulación público-privado \\
\hline & Sescentralización del poder nacional \\
\hline & Articulación nivel nacional-regional-local \\
\hline & Rol del actor privado \\
\hline Capital social & $\begin{array}{l}\text { Nuevas organizaciones sociales } \\
\text { Participación vinculante }\end{array}$ \\
\hline
\end{tabular}

Fuente. Elaboración propia.

Una vez calificada cada una de las variables presentadas en el cuadro $\mathrm{N}^{\circ} 1$ se construyó un diagrama que da cuenta de los grados de compromisos de los distintos actores antes del desastre y en la etapa de reconstrucción actual. En la parte final del artículo se discute qué actores públicos o privados requieren un mayor rol en la estructura de reconstrucción para avanzar hacia una gobernanza resiliente.

\section{Capitalización del desastre como manifestación de procesos de exclusión socioespacial en ciudades intermedias y menores de Chile}

Se postula la capitalización del desastre como una oportunidad de inversión frente a 
desastres guiando nuevas lógicas de reconstrucción y construcción exclusionaria, ya que algunos quedan relegados a una condición de vulnerabilidad, en tanto sujetos con menor poder de negociación. Esto último refiere no solo a familias de bajos ingresos, también a ciudades intermedias y menores cuya administración del riesgo está centralizada y resuelta generalmente desde la ciudad de Santiago. Surgen entonces las siguientes interrogantes ¿para quién o quiénes los desastres constituyen oportunidades de inversión? En tal sentido Klein (2008) postula que cualquier shock o perturbación son utilizados deliberadamente para permitir la puesta en obra de reformas económicas neoliberales mayores que sería imposible de imponerlas en tiempos normales. Por otro lado, para Zibechi (Klein, 2008) los desastres son una oportunidad para que los movimientos sociales puedan demandar transformaciones desde un enfoque de derecho, siendo el primero el derecho a la vivienda y el segundo el acceso a la ciudad. Por tanto, el escenarío postcatástrofe se transforma en una posibilidad de emancipación de los movimientos sociales, pero al mismo tiempo, un desastre puede desencadenar nuevas fracturas sociales y la emergencia de nuevas formas de liderazgo y exclusión social.

Desde la dimensión de la capitalización postdesastre, la gentrificación se vuelve un proceso latente considerando que las ciudades intermedias y menores están limitadas a una estructura territorial fuertemente centralista. Lo latente se visibiliza en la desarticulación de los actores territoriales; los mecanismos de desplazamiento y relocalización, así como también en la retirada del Estado "en esas funciones y una mayor importancia del sector privado en dichas tareas" (Arenas et al., 2010: 3).

En este artículo se comprende la gentrificación como proceso de transformación socioespacial y de intensa movilidad residencial que afecta a las áreas centrales y pericentrales consolidadas, pero también a espacios afectados por reconstrucciones lideradas por agentes privados. Los gentrificadores están representados por agentes inversores que capturan los beneficios de espacios deteríorados, tugurizados o en ruinas, entre estos destacan agentes inmobiliaríos, comerciales y particulares dispuestos a capturar la renta potencial luego de un desastre como un terremoto o tsunami. La gentrificación como fenómeno latente en espacios postdesastre lleva a plantearse la interrogante: ¿en qué medida los mecanismos de desposesión a los que se ven sometidos los sujetos sociales los vuelve sujetos vulnerables frente a los especuladores?

En esta investigación se asume una noción más provincial de la gentrificación que proponen González y Hodkinson (2014) al momento de explicitar las particularidades del proceso fuera de Londres, es decir, más allá de las ciudades globales que tienen un parque de viviendas con potencial de gentrificación, así como sujetos sociales con estilos de vida y gustos gentrificadores. Lo provincial de la gentrificación se justifica dado que son dos espacios afectados por un terremoto y un tsunami, liberando suelo capitalizado por agentes privados y públicos. Asumiendo que la gentrificación advertiría formas exclusionarias de acceso al suelo, se comprende la exclusión como la aglomeración territorial de las familias perteneciente a un mismo grupo social ya sea en términos sociales, territoriales o étnicos (Sabatini \& Brain, 2008), la relocalización de las familias vulnerables y afectadas provocaría la fractura del tejido social exponiéndolas así, a latentes procesos de gentrificación. Desde la perspectiva del desastre lo más cuestionable es quienes son desplazados, hacia qué sectores son relocalizados y cuál es el sentido que las familias le asignan a los nuevos sitios residenciales. Para los dos casos de estudio los desplazados fueron principalmente familiares de bajos ingresos con menor poder de negociación, o bien, familias afectadas por el trauma. Las implicancias de un desastre "son básicamente sociales en la medida que se destruye el territorío, mueren personas y la estructura social sufre una fractura" (Quinceno, 2015: 3). Se desarticulan además, redes sociales y familiares que dan sustento a la vida cotidiana y que dificultan las posibilidades de recomposición socioespacial luego del desastre (Contreras y Beltrán, 2015). Los erradicados y relocalizados son proclives a la gentrificación, que "debiera ser abordada a través de un punto de vista que contemple la diversidad de matices y las espacialidades conflictivas del neoliberalismo urbano" (Brenner et al., 2010: 13). 
Desde la planificación territorial del desastre, Arenas et al. (2010) sostienen que esta podría resolver parte de los cuestionamientos previos en tanto establezca criteríos en términos de políticas públicas a nivel nacional o regional/local no solo orientado a la protección de zonas condicionadas dada su función crítica desde el punto de vista natural, patrimonial, social o económico" (p. 5). Se debiese replantear también, una política transversal del borde costero permitiendo un diálogo más fluido entre las regiones costeras más allá de sus delimitaciones administrativas.

Si se estableciera una política pública pensada desde la complejidad y multifuncionalidad del término riesgo, disminuirían las posibilidades de desplazamiento y relocalización hacia otros espacios sometidos a otros riesgos a veces invisibilizados. Siguiendo a Marcuse (1986) el desplazamiento respondería al aumento del precio de los arriendos debido a la influencia y tendencias del mercado. En escenaríos de reconstrucción postdesastre podrían presentarse al menos dos tipos de desplazamiento: uno directo derivado de acciones físicas y económicas como parte de la necesidad de reconvertir espacios y relocalizar a la población afectada, y, otro indirecto derivado del abandono de las viviendas y los vecindaríos -falta de inversión e interés público o privado- o bien, las menores posibilidades de negociación de familias menor pagadoras de suelo, con menor poder de negociación, o bien, afectadas por el trauma y postdesastre.

\section{Dos experiencias de reconstrucción en núcleos urbanos menores de Chile. Constitución y Dichato}

Parte de las investigación sobre desastres tienden a concentrarse en grandes ciudades (Mitchell, 1999) dado que estas son las que concentran un mayor volumen de población, o bien porque existe una planificación territorial centralista que no asigna mayor poder de decisión a espacios menores. Cabría cuestionarse entonces ¿en qué medida se diseñan políticas y estrategias que incorporen las ciudades intermedias y los núcleos urbanos y rurales menores más allá de su talla de- mográfica? Esto último, exige pensar que un desastre puede estar limitado por las posibilidades de establecer vínculos en los procesos de toma de decisiones entre agentes locales, regionales y nacionales (Bellet y Llop, 2004), es decir, reconstruirse a partir de las redes y flujos de proximidad considerando los agentes que construyen territorío.

Es a partir de la década de los años 80 cuando las ciudades intermedias latinoamericanas comenzaron a ser objeto de diferentes investigaciones en la planificación nacional y regional. Borsdorf (2000) analizando entre los años 1974 a 1999 los efectos del tsunami y terremoto de 1960 en la ciudad mediana de Valdivia, observó un crecimiento vertical en el área central, especialmente en los predios que se concentran en el borde río lo que develaría procesos de gentrificación exclusionaria, en tanto antiguos residentes quedaron relegados de la recuperación posttsunami. Identificó todos los sitios sin edificar quedando reducidos a sectores que acogen servicios públicos y privados como resultado de un modelo neoliberal. Ground (2007) analizando el desastre post-Katrina 2002 advierte que son las élites económicas locales las que capturan los beneficios de la destrucción, monopolizando el proceso de planificación y reconstruyendo el paisaje urbano de forma desigual.

En Chile particularmente vinculado a los terremotos y tsunamis desde los años 2000 comienzan a desarrollarse diferentes investigaciones que prestan atención al rol del capital social en el proceso; los efectos sociourbanos del desastre (González Muzzio, 2013; Rasse y Letelier, 2013, Contreras y Beltrán, 2015), la gestión política (Brescianni, 2010), así como también la dimensión psicológica y el estrés producido en los trabajadores luego del desastre (Jiménez y Cubillos, 2010).

Constitución y Dichato se configuran como espacios donde más del $50 \%$ de su población habita en espacios urbanos. Están alejados de las ciudades intermedias y grandes que son parte de su región. Constitución se localiza a más de 97 kilómetros de la ciudad intermedia de Talca, y Dichato está a más de $37 \mathrm{~km}$ de la conurbación ConcepciónTalcahuano. Si bien ambos espacios cuentan con una red de carreteras que aseguran el 
acceso existen ciertas limitaciones espaciotemporales que vuelven más compleja la reconstrucción. Los núcleos estudiados fueron tratados como espacios marginados en cuanto a sus poderes de decisión económica, normativas y de planificación en el marco de la reconstrucción. En Constitución las decisiones estuvieron ancladas en el gobierno central y en Dichato fueron lideradas por el gobierno regional por sobre el local.

En este escenarío se afirma que los dos sitios tiene un alto potencial de redesarrollo urbano por cuanto maximizan el valor potencial del suelo, especialmente aquellos predios ubicados en el borde costero donde se están ejecutando interesantes intervenciones como el Parque de Mitigación en Constitución. Inzulza (2014) plantea que una estrecha relación entre el Estado y el sector privado parece ser la principal estrategia para el desarroIlo de los centros urbanos deteríorados. En el caso específico de Constitución aún no existe consenso sobre criteríos de densidad y modalidades de ocupación del borde río Maule. La desarticulación de las redes sociales y los cambios en el espacio urbano tienden a estar vinculados a la llegada de mejores pagadores del suelo que invierten en fases de obsolescencia y deteríoro. Harvey (2008) hace explí- cito el término acumulación por desposesión cuando el fenómeno de acumulación de capital se consolida a través de la expulsión de hogares de más bajos ingresos, y las transformaciones de distintas formas de propiedad en propiedad privada acumulada queda en manos de pocos agentes. Sin embargo, la incertidumbre del Parque de Mitigación al menos los tres primeros años luego de la fase de impacto o emergencia llevan a sostener la tesis de una acumulación por desposesión al menos desde los primeros años del $27 \mathrm{~F}$, especialmente en manos de agentes privados.

Constitución se encuentra ubicada en la orilla sur de la desembocadura del río Maule en el océano Pacífico (Figura № 1). Limita al sur y oeste por numerosos cerros y colinas siendo el más importante el cerro Mutrún cerca de la desembocadura del río. Se localiza a $88 \mathrm{~km}$ del epicentro de terremoto y tsunami del 27F. Parte de las viviendas del casco histórico quedaron dañadas y destruidas y el tejido social quedó fracturado tras la relocalización, especialmente de los habitantes del sector La Poza (Contreras y Beltrán, 2015). En la Figura $N^{\circ} 1$ se demarca con línea negra la planta urbana más afectada por el terremoto y en línea gris discontinua, la cota real de inundación tras el tsunami.

Figura $\mathrm{N}^{\circ} 1$

Constitución, Región del Maule, Chile

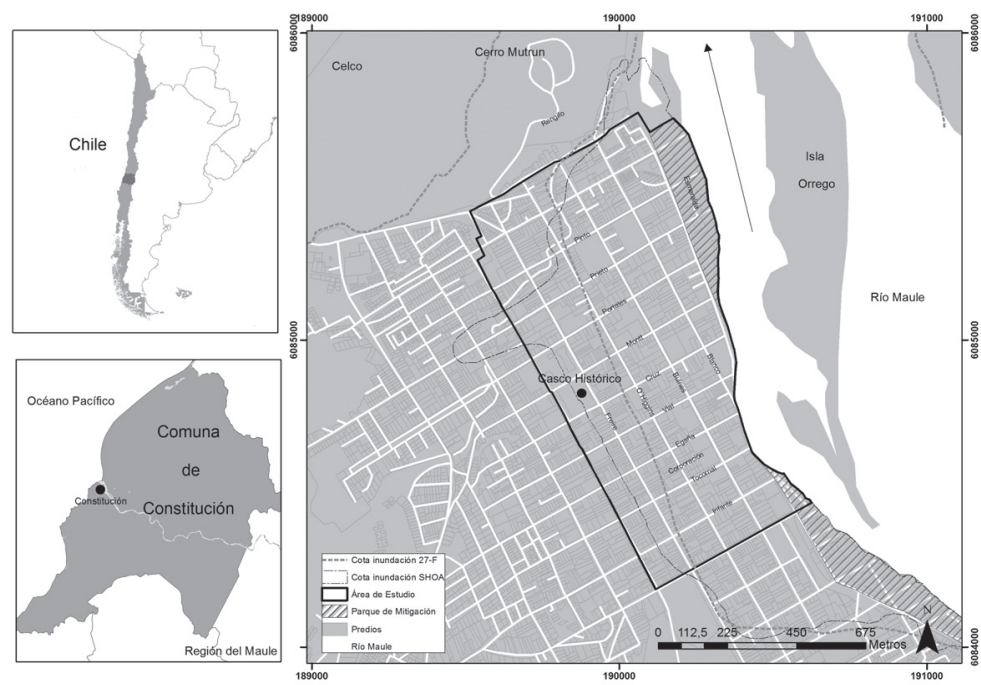

Fuente. Elaboración propia. 
La superficie afectada por el terremoto y tsunami se expone en el Cuadro $N^{\circ} 2$ donde se observa que más del $61 \%$ de los predios de la planta urbana (2.253 en total) fueron afectados por el tsunami. Contreras y Beltrán (2015) aseguran que los afectados tras el terremoto provienen de diferentes sectores de la ciudad. Más del $45 \%$ de las demandas tras el tsunami habitaban la planta urbana de la ciudad, y el resto provenía de las partes altas. Durante la etapa de emergencia, fueron creadas cinco aldeas solidarias: 27 de Febrero, Antofa, Caleta Pellines, La Poza y Puertas Verdes para más de 2.000 personas damnificadas. No hay certeza respecto al porcentaje de familias relocalizadas y aquellas que regresaron a sus residencias, e incluso del número de beneficiados que no vivían en Constitución y que no fueron afectados por el tsunami. A seis años del desastre, los cambios son lentos y las temporalidades de la reconstrucción son cuestionables. La reconstrucción en Constitución fue solventada y gestionada, principalmente, por instituciones del Estado, a través de la construcción de nuevas residencias, entrega de subsidios, mejoramientos de vivienda deterioradas, construcción de nuevos caminos, entre otros. Menores obras resultan de la acción entre agentes públicos y privados.

Las iniciativas privadas y públicas se focalizaron en la recuperación del borde río-mar; la nueva sede de bomberos, la construcción de la biblioteca, el centro cultural y el teatro en torno a la plaza histórica, la construcción de un nuevo edificio de la capitanía marítima en torno al borde río; reconstrucción del muelle en el borde río Maule. Si bien el conjunto de proyectos ha sido significativo pero distante de los 37 proyectos presentados por el Plan de Reconstrucción Sustentable (PRES). Es urgente pensar en una reconstrucción inclusiva que implica no solo asignar una vivienda, sino también definir en el tiempo, acciones, actores y recursos que aseguren la reconfiguración del territorio desde la dimensión de las redes sociales y familiares previas al desastre; el sentido de las prácticas espaciales de los afectados, los mecanismos de acceso al trabajo, a la educación; el derecho a sanarse sicológicamente, entre otras dimensiones invisibilizadas por una reconstrucción centrada en la fase de emergencia o primer impacto.

En términos de cambios demográficos postdesastre, la ciudad de Constitución ha presentado variaciones antes y después del desastre. Según cifras del último Censo del año 2002 en la ciudad residían 46.081 personas siendo un $80,7 \%$ de población urbana y un $19,4 \%$ rural (INE, 2002). Sin embargo, los datos de la Encuesta CASEN para el 2013 revelan un aumento de casi 9.500 habitantes en la ciudad entre el 2002 al 2013 (Cuadro $\mathrm{N}^{\circ}$ 2) no obstante, dada las limitantes censales no existen registros que permitan localizar los nuevos residentes dentro de Constitución en el marco del proceso de reconstrucción, salvo aquellos residentes en viviendas de interés social.

Cuadro $\mathrm{N}^{\circ} 2$

Características sociodemográficas, urbanas y físicas de Constitución y Dichato, antes y después del desastre

\begin{tabular}{|l|r|r|}
\hline \multicolumn{1}{|c|}{ Variables } & Constitución (Comuna) & \multicolumn{2}{c|}{ Dichato (Localidad) } \\
\hline Total población 2002 & 46.081 & 3.388 \\
\hline Total población 2013* & 55.700 & 4.046 \\
\hline Magnitud del evento & 8,8 & 8,8 \\
\hline Total muertos & 91 & 1 \\
\hline $\begin{array}{l}\text { Superficie de inundación } \\
\text { tsunami 27F, 2010 (ha) }\end{array}$ & 2,7 & 6.9 \\
\hline $\begin{array}{l}\text { Cota de inundación (me- } \\
\text { tros) }\end{array}$ & 1 a 3 & 1 a 5 \\
\hline
\end{tabular}



MENORES E INTERMEDIAS CHILENAS AFECTADAS POR EL TERREMOTO Y TSUNAMI DEL $27 F 2010$.

LOS CASOS DE CONSTITUCIÓN Y DiCHATO

continuación Cuadro $\mathrm{N}^{\circ} 2$

\begin{tabular}{|c|c|c|}
\hline \multirow{2}{*}{$\begin{array}{l}\text { Porcentaje Predios afecta- } \\
\text { dos por tsunami }\end{array}$} & 61 & \multirow{2}{*}{65,85} \\
\hline & (1.392 de 2.253$)$ & \\
\hline $\begin{array}{l}\text { Total subsidios de vivien- } \\
\text { das entregados (familias) }\end{array}$ & 1.390 & $\mathrm{~S} / \mathrm{I}$ \\
\hline $\begin{array}{l}\text { Total familias relocalizadas } \\
\text { nuevas poblaciones }\end{array}$ & 430 & 648 \\
\hline Total familias radicadas & \multirow{2}{*}{$\begin{array}{r}192 \text { (Villa O’Higgins, } \\
\text { Francisco Mesa Seco y Aro- } \\
\text { mo })\end{array}$} & \multirow{2}{*}{265} \\
\hline En sitio residente & & \\
\hline $\begin{array}{l}\text { Total familias erradicadas } \\
\text { en espacios de proximidad }\end{array}$ & $\begin{array}{r}44 \text { que residían en la zona } \\
\text { cero La Poza }\end{array}$ & No existen casos \\
\hline Total familias erradicadas & $\mathrm{S} / \mathrm{I}^{*}$ & 73 \\
\hline
\end{tabular}

*S/I: Sin información

Fuente. Elaboración propia a partir de Censo, 2002 y Casen 2013; Contreras y Beltrán, 2015; Observatoiro del Ministerío de Desarrollo Social.

Por el otro lado, Dichato (Figura y Cuadro $\mathrm{N}^{\circ}$ 2) es una localidad turística y pesquera ubicada en la VIII Región del Biobío, perteneciente a la comuna de Tomé en la provincia de Concepción. Se localiza a $9 \mathrm{~km}$ de la comuna de Tomé y a $37 \mathrm{~km}$ de la ciudad de Concepción. Posee 4.046 habitantes albergando menos del $10 \%$ de los residentes del municipio de Tomé (56.426 habitantes proyectados al 2012, INE, 2013). Esta bahía fue fuertemente afectada por el terremoto y tsunami del $27 \mathrm{~F}$ arrasando con su área urbana histórica, tal como Borsdorf (2000) evidenció para la ciudad intermedia Valdivia posteríor al terremoto y tsunami de 1960.

Figura $\mathrm{N}^{\mathrm{o}} 2$

Dichato, Región del Biobío, Chile

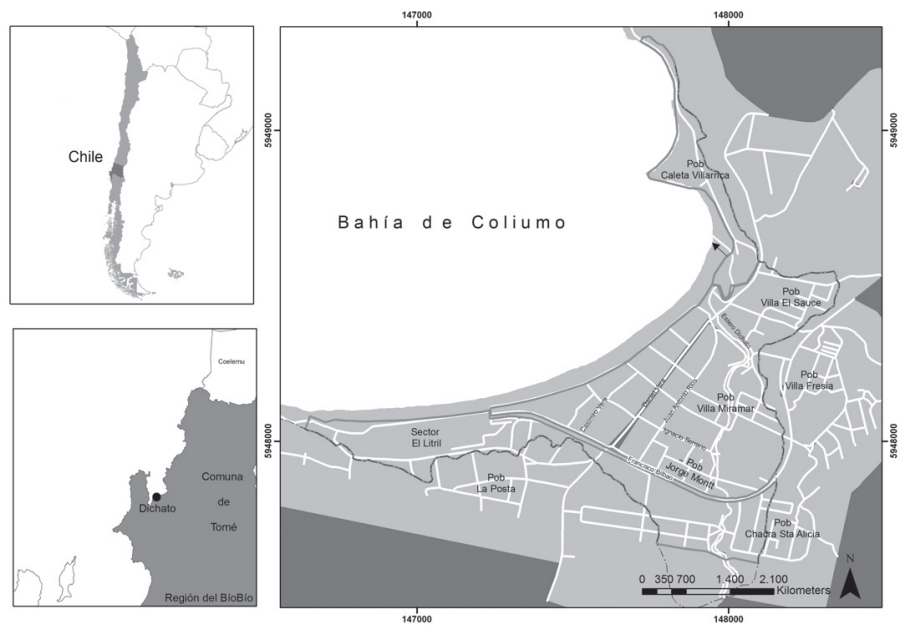

Fuente. Elaboración propia. 
En cuanto a la superficie afectada por el terremoto y tsunami, el $65,8 \%$ de la localidad quedó fuertemente dañada (PRBC-18, 2012) quedando a resguardo los sectores La Posta, Villa Fresia y Chacra Santa Alicia. Durante la etapa de emergencia fueron creadas cuatro aldeas solidarias El Molino (la grande de Chile con más 450 familias), La Iglesia, El Esfuerzo y Nuevo Amanecer. No hay certeza respecto al porcentaje de familias relocalizadas y de aquellas que regresaron con sus medios a sus residencias. A seis años del desastre la reconstrucción responde a obras urbanas de mitigación más que de planificación del desastre entre estas: La Costanera, Parque de Mitigación en el Borde Costero, el encauzamiento del estero de Dichato y el recientemente construido Bosque de Mitigación en la desembocadura del mismo estero. Por otro lado, las soluciones habitacionales han incorporado la construcción de nuevas poblaciones como Población El Sauce, Villa Miramar, Paula Jaraquemada, Villa Horizonte, La Posta, además de los nuevos edificios construidos en el de Litril y viviendas en sitio propio en la población Jorge Montt.

La importancia de Dichato como caso de estudio radica en factores vinculados a su condición geográfica, conformada por los deltas del estero Vegas de Coliumo y estero Dichato $y$, limitada por la cordillera de la Costa. Estas condiciones geográficas la hacen comparable al caso de Constitución. Dichas condiciones potenciaron los efectos del volumen de agua que ingresó por el estero y por el borde costero donde se localizaba gran parte de la actividad comercial y turística. La acción destructiva aumentó por el estero de Dichato aguas arriba con una columna de agua que alcanzó una altura de 6,5 metros, destruyendo principalmente viviendas de primera residencia (PRBC-18, 2012).

El espacio urbano de Dichato fue casi completamente devastado, implicando una rápida reacción por parte del gobierno central y regional al invertir y generar proyectos urbanos y comerciales. Inicialmente, las operaciones estuvieron abocadas a recuperar el borde costero y a mitigar los efectos causados por el tsunami en las desembocaduras de los esteros. Por otro lado, el caso de estudio develó a una comunidad con alta capacidad de organización y reacción, la cual se fracturó durante el proceso de relocalización y asignación de recursos estatales.

\section{¿Reconstrucción exclusionaria en Constitución y Dichato?}

Ambos casos de estudio representan formas exclusionarias de relocalización y erradicación, estando insertos en espacios urbanos afectados por múltiples riesgos. Esto último devela parte de las deseconomías y costos hundidos derivados de una reconstrucción pensada y planificada desde el corto plazo. Se alude a exclusionarío en tanto los sujetos sociales afectados, especialmente hogares de bajos ingresos fueron desplazados del área urbana a espacios más alejados, involucrando nuevos costos para las familias no solo en términos monetarios, también desde sus prácticas cotidianas y la desarticulación de las redes sociales y familiares. En este apartado se discuten los tipos de relocalización, desplazamientos en las dos zonas de investigación La clasificación presentada en el Cuadro $\mathrm{N}^{\circ} 3$ resulta del análisis de las entrevistas en profundidad, y de los discursos de actores claves en el marco de la reconstrucción. 
Cuadro $\mathrm{N}^{\circ} 3$

Tipos de relocalización y desplazamiento en Constitución y Dichato

\begin{tabular}{|c|c|c|}
\hline $\begin{array}{l}\text { Tipo de Desplazamiento/ciu- } \\
\text { dad }\end{array}$ & Dichato & Constitución \\
\hline \multirow{3}{*}{ Tipo de Relocalización } & $\begin{array}{l}\text { En sitios propios conformando } \\
\text { poblaciones }\end{array}$ & En espacios de proximidad \\
\hline & $\begin{array}{l}\text { Fuera del área urbana y en zonas } \\
\text { de riesgos remoción en masa }\end{array}$ & $\begin{array}{l}\text { Relocalizados fuera del } \\
\text { área urbana, especialmente } \\
\text { en zonas residenciales para } \\
\text { viviendas de interés social, } \\
\text { localizadas sobre espacios } \\
\text { con riesgos de remoción } \\
\text { en masa }\end{array}$ \\
\hline & $\begin{array}{l}\text { Dentro del área urbana y en nue- } \\
\text { vas soluciones habitacionales }\end{array}$ & $\begin{array}{l}\text { Dentro del área urbana y } \\
\text { en nuevas soluciones habi- } \\
\text { tacionales }\end{array}$ \\
\hline \multirow[b]{2}{*}{ Radicados } & En sitio residente & En sitio residente \\
\hline & $\begin{array}{l}\text { Poblaciones existentes al interior } \\
\text { de área urbana consolidada de la } \\
\text { localidad }\end{array}$ & $\begin{array}{l}\text { Población radicada al in- } \\
\text { terior del área urbana en } \\
\text { sectores de demolición de } \\
\text { viviendas posterremoto }\end{array}$ \\
\hline \multirow{2}{*}{$\begin{array}{l}\text { Nueva migración (datos invisi- } \\
\text { bilizados) }\end{array}$} & $\begin{array}{l}\text { Familias que provienen de San- } \\
\text { tiago y Talcahuano }\end{array}$ & $\begin{array}{l}\text { Familias que provienen de } \\
\text { Santiago y Concepción }\end{array}$ \\
\hline & Familias nucleares dichatinas & Familias nucleares maulinas \\
\hline
\end{tabular}

Fuente. Elaboración propia a partir de entrevistas y trabajo de campo, 2012, 2013 y 2014.

El Cuadro No 3 muestra tres tipos de movimientos residenciales: relocalizados, radicados y nuevas migraciones internas:

\section{Relocalizados y desplazados del riesgo al riesgo}

En la Figura $\mathrm{N}^{\circ} 3$ se especializa las zonas de relocalización, radicación y desplazamiento de población posterremoto $27 f$ en la ciudad de Constitución. De manera específica, un primer tipo de desplazamiento está re- presentado por la relocalización en espacios de proximidad. En segundo lugar, las familias fueron relocalizadas fuera del área urbana bajo el discurso de que no existía suelo disponible en la zona de riesgo por tsunami. Lo que los gobiernos regionales ni nacionales advirtieron es que las familias fueron relocalizadas del riesgo por tsunami al riesgo por incendio y remoción en masa. Estos movimientos advierten nuevas formas de exclusión en tanto se asignó vivienda pero se negó o se olvidó el derecho a la movilidad al menos en los primeros seis años de ocurrido el desastre. 


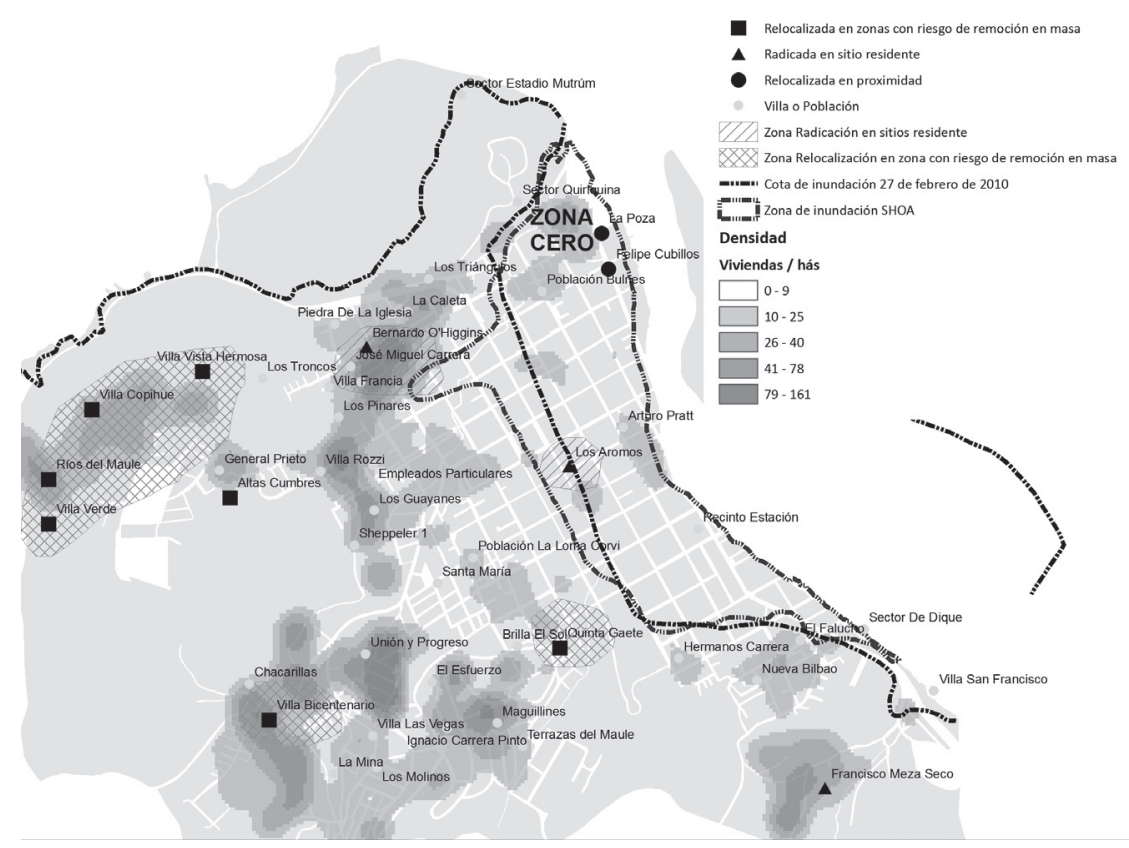

Fuente. Elaboración propia.

Indistintamente al tipo de desplazamiento, desde las entrevistas se concluye que las familias relocalizadas en zonas residenciales donde habitaban grupos sociales medios y medios altos como el sector Villa Copihue o Villa Verde en Constitución (Figura $N^{\circ} 3$ ) tienen mayores grados de satisfacción residencial, en comparación con hogares desplazados hacia sectores de viviendas de interés social como por ejemplo, quienes habitan en Cerro Centinella o Quinta Gaete (Figura No 4) donde coexisten con hogares de similares condiciones económicas, pero con diversos orígenes residenciales. El grado de satisfacción de quienes viven en Villa Copihue y Villa Verde está vinculados al tipo de vivienda, su materialidad y tamaño, así como el entorno en el que se encuentra.

En Constitución el área más afectada fue el sector La Poza (Figura $N^{0} 3$ ) donde la destrucción abarcó casi el 99\% de los predios. Una de las primeras acciones fue la construcción de 255 mediaguas de las cuales más del $80 \%$ de las familias han recibido subsidios de relocalización en sitio residente. Más del $45 \%$ de las demandas tras el tsunami habi- taban en el casco histórico de la ciudad, y el resto provenía de los cerros de Constitución. Durante la etapa de emergencia fueron creadas cinco aldeas solidarias 27 de Febrero, Antofa, Caleta Pellines, La Poza y Puertas Verdes (Figura No 4) para más de 2.000 personas damnificadas. En diciembre del año 2010 se firmó un convenio entre la empresa Arauco, constructoras y SERVIU Maule a objeto de ejecutar cinco proyectos habitacionales en Constitución para 1.390 familias beneficiadas con el subsidio de vivienda. Los proyectos son Quinta Gaete con 320 soluciones habitacionales; Comité Las Cumbres con 220 viviendas; Calle Prieto con 400 viviendas en una primera etapa (1.400 en total) y La Poza con 50 residencias denominadas tsunamiresilientes por el Ministerío de Vivienda y Urbanismo. Estas últimas utilizaron la tipología Elemental representada en viviendas aparentemente "tsunami-resilientes" (Figura $N^{\circ}$ 3). La empresa Arauco, también gestionó la construcción de viviendas para sus trabajadores, a través del conjunto residencial Villa Los Verdes (Figuras $\mathrm{N}^{\circ} 3$ y $\mathrm{N}^{\circ}$ 5) en la parte sur-poniente de la ciudad. Dentro de las soluciones habitacionales, el Servicio de 
Vivienda y Urbanismo (SERVIU) de la Región del Maule informó que en Constitución se inauguraron dos conjuntos habitacionales afectados por el terremoto, especialmente por daño causado a las viviendas o el desplome de algunos edificios de departamentos. Se trata del conjunto Villas Las Cumbres que benefició a 220 familias con una inversión total de $\$ 3.500$ millones. En la Figura $N^{\circ} 3$ se espacializa la densidad de viviendas postdesastre siendo las poblaciones Bicentenarío, La Unión, Valle Verde y Copihue las que tienen densidades superíores a 41 viv/ha. En segundo lugar, destaca el emblemático Conjunto Cerro O'Higgins espacio residencial que colapsó durante el terremoto. Durante la emergencia se entregaron mediaguas a las familias damnificadas. Un $21,7 \%$ de las familias instaló una vivienda de emergencia dentro del mismo lote; el $28,6 \%$ en un terreno cedido por un familiar, amigo, otros; un $8 \%$ aproximadamente fue relocalizada a aldeas solidarias. Respecto al 41,6\% restante no existe información certera respecto a si el grupo familiar persistió en su residencia, se trasladó a otra ciudad, o bien, se encuentra en otra condición (Contreras y Beltrán, 2015). La reconstrucción en sitio residente aumentó la densidad lo que devela nuevos conflictos al interíor de los conjuntos residenciales: arribo de familias extendidas vinculadas a residentes históricos de la ciudad; Ilegada de familias que nunca habitaron en Constitución; beneficiados de subsidios entregados antes del desastre, conflictos entre diferentes hogares dados los diversos orígenes residenciales, entre otros.

\section{Condiciones habitacionales de las familias afectadas postdesastre $27 \mathrm{~F}$.}

Se reconocen cuatro tipos de soluciones habitacionales. En primer lugar, están aqueIlos residentes que luego de cuatro años lograron acceder a una vivienda próxima al sector de La Poza (Figura $N^{\circ} 3$ ). Se trata de familias de pescadores con fuertes liderazgos aunque muchos de estos resultan desconocidos para los beneficiados con subsidios para viviendas de interés social. Otras familias en cambio, recibieron subsidios en sectores donde residen hogares de bajos ingresos (Figura $\mathrm{N}^{\circ} 4$ ), induciendo indirecta o directamente nuevas formas de exclusión al interíor de la ciudad de Constitución. Un tercer grupo representa a aquellos relocalizados hacia sectores de ingresos medios y medios altos (Figura $\mathrm{N}^{\circ}$ 5), localizados en Villa Los Verdes y Los Copihues, es decir en las áreas de expansión suburbanas de grupos medios y medios altos. Finalmente, un cuarto grupo está representado por las familias localizadas en sitio propio siendo casos emblemáticos las 192 familias que habitan en Villa O’Higgins, Los Aromos, y Francisco Mesa Seco (Figura No 3) quienes se configuran como los casos más representativos de resistencias al hábitat.

Figura $\mathrm{N}^{\circ} 4$

Constitución. Relocalizados en zonas con riesgos en remoción en masa y espacios residenciales donde habitan hogares de ingresos bajos

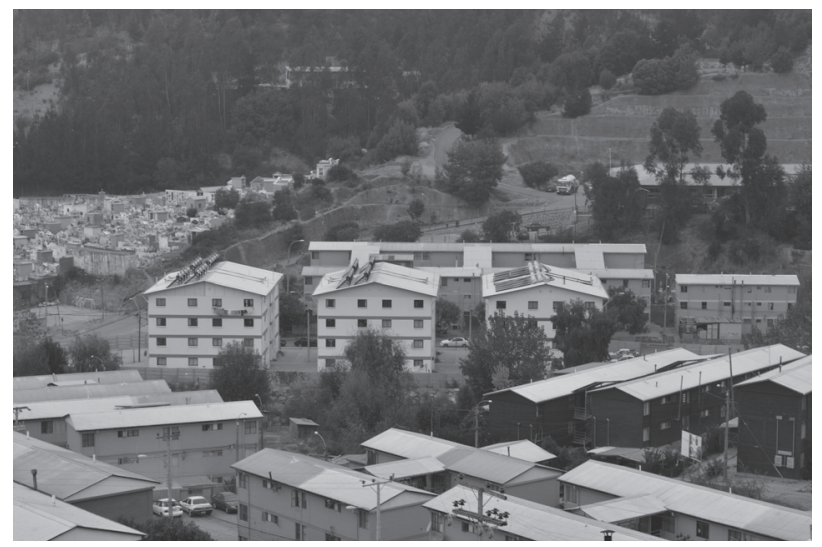

Fuente: Archivo personal de los autores. 
Figura $\mathrm{N}^{\circ} 5$

Constitución. Relocalizados en zonas con riesgos en remoción en masa y espacios residenciales donde habitan hogares de ingresos medios y medios altos

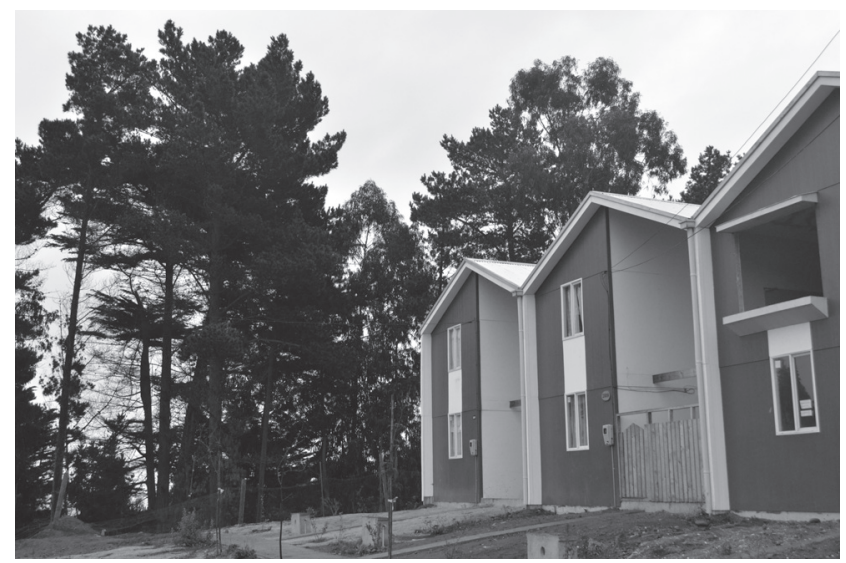

Fuente. Archivo personal de los autores.

En Dichato se generaron espacios urbanos adecuados para la construcción de las obras de mitigación en las dos zonas más vulnerables a la exposición de amenazas de tsunami (Figura $\mathrm{N}^{\circ}$ 2). Esta es una primera diferencia con Constitución dada la escala de los espacios y el nivel de compromiso y articulación del gobierno regional con el nivel central. En torno al estero de Dichato se expropiaron 25 propietaríos con una total de $6.147,2 \mathrm{~m}^{2}$ (DOH, 2012) de los cuales según antecedentes del Servicio de Impuestos Internos, 14 eran propietaríos irregulares. Por otro lado, la misma operación se generó en el borde costero con la finalidad de construir el Parque de Mitigación y la Costanera (Figura $\mathrm{N}^{\circ}$ 6), expropiándose 48 propietaríos de los cuales un $80 \%$ eran segunda residencia y un $20 \%$ equipamiento comercial, es decir, restaurantes y pequeños locales comerciales. No existen datos con los cuales se pueda determinar si las familias erradicadas fueron relocalizadas en la misma localidad o desplazadas dentro de la comuna (PRBC-18, 2012).

Las nuevas poblaciones en Dichato se relocalizan fuera del casco histórico tradicional como Villa Horizonte (Figura $N^{\circ} 6$ ), un espacio sometido a riesgos en remoción en masa no previstos ni normados dada la carencia de una normativa que garantice y resguarde los conjuntos residenciales. La desvinculación inicial con Dichato histórico fue uno de los elementos más cuestionados por los entrevistados, junto con la localización de las viviendas en espacios próximos a riesgos de remoción en masa. Conjuntamente, los costos ocultos de la relocalización se reafirman en los discursos de algunas familiares cuyos lazos familiares y redes sociales quedaron fracturados espacialmente, al igual que en Constitución. Una dirigenta de Villa Horizonte hace explícita las deseconomías de una relocalización postdesastre:

"En Dichato yo tenía acceso a todo, a la mano, la escuela estaba al lado mío, los colectivos pasaban por al lado mío, eso no se lo cambio por esto o sea, imagínate lo que es subir de allá arriba todo, te mojas, que te sientes aislada porque el hecho de vivir aquí arriba, ya es como otra parte, ya no eres parte de Dichato, o sea, de ¿dónde eres?, no yo soy de la Villa, a ¿dónde vives tú?, no yo vivo en Dichato, o sea voy a Dichato a comprar, o sea yo no le digo a mi hija anda al costamar a comprar, o anda al beach a comprar, no, anda a Dichato".

Desde el relato anteríor se advierte el sentido de identidad de los relocalizados en los sitios preexistentes, así como también los mecanismos que deben generar para resignificar territoríos no escogidos. 
Figura $\mathrm{N}^{\circ} 6$

Dichato. Tipos de relocalización y desplazamiento postdesastre

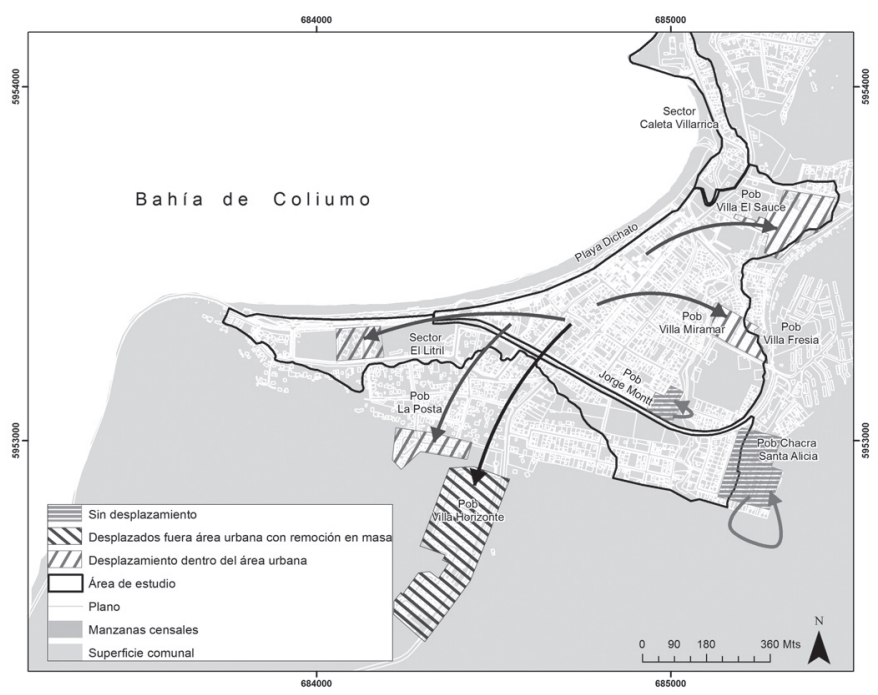

Fuente. Elaboración propia.

La Figura $N^{\circ} 6$ devela el patrón de ubicación de los nuevos conjuntos resultantes de la relocalización: Población El Sauce con 176 soluciones habitacionales, Villa Horizonte con 210 viviendas, Edificios Litril con 128 departamentos y Población La Posta con 35 viviendas. La radicación se materializó a partir de la construcción de nuevos conjuntos residenciales en las zonas afectadas de Constitución y Dichato. Las modalidades de construcción consideraron mecánica de suelo, reduciendo así las posibilidades de destrucción de los conjuntos habitacionales emplazados sobre suelos arcillosos y limosos. En Dichato se construyeron 362 soluciones habitacionales en sitio propio entre las cuales destacan el sector Jorge Montt con 47 viviendas de 2 pisos albañilería primer piso y/o vivienda palafito tal como se presenta en la Figura $N^{\circ} 7$ sector Chacra Santa Alicia con 115 viviendas de 2 pisos albañilería primer piso; sector Paula Jaraquemada con 27 viviendas en su mayoría palafito, Caleta Villarrica con 11 viviendas palafito y finalmente, 65 viviendas dispersas en el área urbana de Dichato expuestos en la Figura $N^{\circ} 8$.

Figura $\mathrm{N}^{\circ} 7$

Dichato. Tipos de viviendas tipo palafitos, Sector Caleta Villarrica

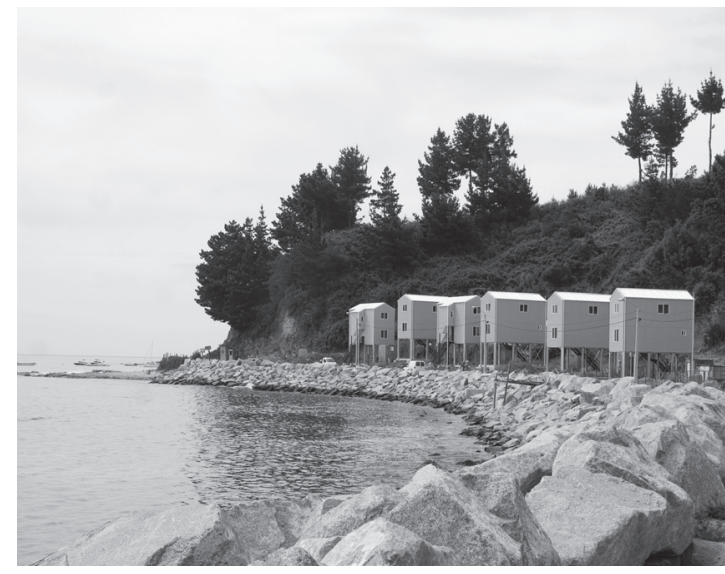

Fuente: Archivo personal de Ignacio Bisbal 
Figura $\mathrm{N}^{\circ} 8$

Dichato. Tipos de viviendas en la zona urbana afectada por el tsunami $27 \mathrm{~F}$

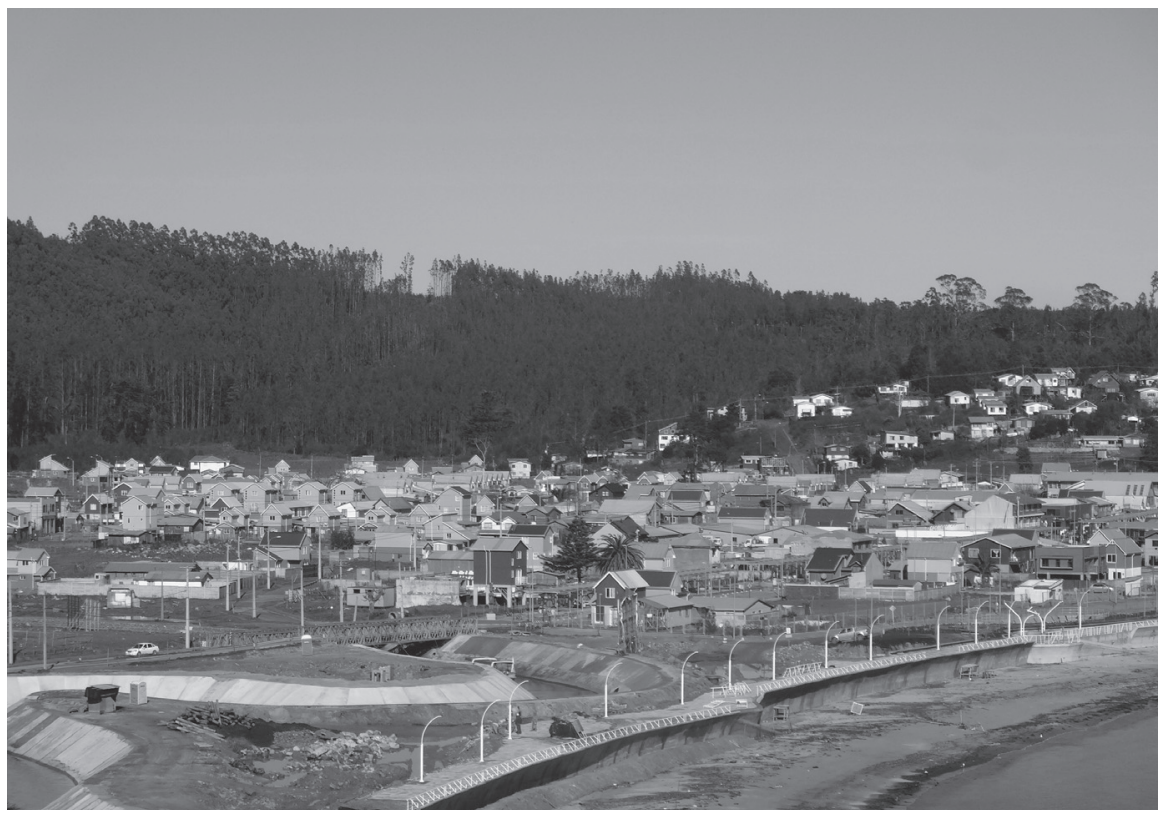

Fuente: Archivo personal de los autores.

Al año 2012 la población había aumentado en $0,16 \%$ después del $27 \mathrm{~F}$, Ilegando a 4.046 habitantes, por lo que se presume se formalizaron nuevas familias a partir de hogares troncales $y / 0$ nucleares residentes en Dichato (PRBC-18, 2012).

\section{Nueva migración interna: ¿capitalizando con el riesgo de desastre?}

Tanto en Constitución como en Dichato, entrevistas a antiguos residentes como agentes públicos develan una reconstrucción viviendista (Rasse y Letelier, 2013; Contreras y Beltrán, 2015), constituyéndose en mecanismos de acceso a la vivienda, ya sea para aquellos allegados o bien, para familias de diferentes ciudades del país que esperaban la entrega de un subsidio habitacional previo al 27F. La falta de catastros e información sobre títulos de dominios durante la fase de emergencia complejizó las posibilidades de identificar qué hogares podrían acceder a un subsidio del Estado. En los dos casos de estudio se identificaron familias que se acogieron a viviendas de interés social postdesastre proviniendo de Santiago, Talcahuano y Concepción. Esto último evidencia el sentido de oportunidad del desastre como mecanismo de acceso a la vivienda:

"Aquí llegó gente que nunca había vivido en Constitución. Mire cuando yo recibí mi subsidio en Cerro Centinella, tuve que convivir con gente que nunca fue amiga ni familia. Esta cuestión se prestó para que otros se aprovecharan. Personas que nunca vivieron aquí. Yo me cambié de La Poza donde tenía mi gente, a una población con muchos problemas, como drogas, o curaos. Si bien en La Poza habían curados nadie golpeaba a las mujeres". Hombre, 68 años, pescador, propietarío de un departamento en un Edificio de Cerro Centinella.

\section{En Dichato el discurso es similar:}

"Aquí llegó gente de todas partes, hasta desde Santiago, si tú ves los departamentos están la mayoría vacíos, si hasta les 
han colocado candados por fuera para que no les roben las cosas y después los arriendan en verano". Mujer, 62 años, propietaria departamento en el sector de Litril.

Estos nuevos comportamientos tanto individuales como colectivos emergen durante el período postdesastre, reflejando la flexibilidad y adaptabilidad del tejido social a la nueva situación y su capacidad para gestionar recursos acordes a los problemas que deben enfrentar (González, 2013). Si a lo anteríor se agrega su condición de núcleos urbanos menores, el poder de decisión frente al acceso al suelo y a la vivienda está determinado por instituciones regionales y/o nacionales y por un urbanismo pro empresarial y centralista. En Dichato algunas familias beneficiadas de los subsidios del gobierno centrales hacían uso de las viviendas de interés social como segunda residencia, especialmente en períodos estivales. Emerge así, una capitalización del desastre que no es exclusiva al mercado, también a demandas residenciales que residen en los sitios afectados o que bien, arriban desde diferentes espacios frente a las dificultades o tiempos de espera para acceder a una vivienda de interés social.

\section{Construyendo y preparando territoríos resilientes en ciudades intermedias y menores de Chile}

Este apartado tiene como propósito relevar las diferencias entre Constitución y Dichato en términos del nivel de articulación de los agentes de políticas públicas, así como también el nivel de incorporación de la comunidad en los procesos de reconstrucción. La Gobernanza del desastre es un concepto que plantea una discusión sobre la gobernabilidad del riesgo y la forma como diferentes actores se articulan a objeto de definir temporalidad y espacialidad de las acciones. La gobernanza pone en tensión las formas de ocupar el espacio (Tierney, 2012) y el rol de las ciudades y espacios menores en dicho proceso. Las lecciones desde los dos casos de estudios y la forma de abordar la planificación postdesastre exigen anidar nuevas formas de planificar, de articular agentes público-priva- dos y comunidad, prestando atención a la necesidad de fortalecer los estados y las formas de gobiernos locales, regionales y nacionales de largo plazo en espacios que requieren un tratamiento diferente dada su condición de riesgo, amenaza y vulnerabilidad.

Arenas, et al. (2010) sostienen que conceptos como gobernanza, riesgo, gestión territorial estratégica, entre otros, más que ser términos antagónicos son complementaríos. Sin embargo, es necesarío progresar "hacia una planificación territorial que se adapte de modo constante a las dinámicas de uso del espacio; que sea gobernable, en el entendido de incorporar a los distintos actores que concurren en un lugar determinado acarreando los intereses de la sociedad; y que sea democrática, en el sentido que el Estado debe ponderar el peso de la opinión de estos actores" (p. 3). Por tanto, en este artículo se recurre a la gobernanza resiliente en la medida en que involucra el reconocimiento de quienes habitan el espacio, la memoria colectiva respecto a como enfrentar un desastre, y las modalidades de acción y articulación con diferentes jerarquías territoriales no solo en las fases de impacto, sino durante la reconstrucción de largo plazo.

La extendida aplicación de los principios neoliberales ha introducido el enfoque que afirma que los agentes privados son más eficientes que el gobierno y su engorroso aparato público, tanto en lo económico como en lo social (Bello, 2006: 97-115). Sin embargo, esa eficiencia redunda en una desigualdad para aquellos con menor poder de negociación. Al parecer, dicha lógica fue la que imperó la forma de planificación del desastre en Constitución a diferencia de lo que sucedió en Dichato, al menos en los dos primeros años posteríores al 27F. Esta lógica entendida y aplicada desde el mismo aparato público ha permitido en Chile la privatización de muchos ámbitos tradicionalmente públicos. Con el proceso de reconstrucción se han privatizado también los procesos de gestión (Letelier y Boyco, 2011), aunque más bien la reconstrucción es signo de regulación de corto plazo, y de escasos mecanismos de planificación y gestión del desastre. El Cuadro $\mathrm{N}^{\circ}$ 4 resume algunas dimensiones que se consideran claves en una reconstrucción resiliente. 
Cuadro $\mathrm{N}^{\circ} 4$

Gobernanza del Desastre en Constitución y Dichato, antes del desastre y en la fase actual de reconstrucción

\begin{tabular}{|l|l|l|}
\hline \multicolumn{1}{|c|}{ Dimensión } & Antes y Durante el Desastre & \multicolumn{1}{c|}{ Gobernanza Resiliente } \\
\hline Reconstrucción Medio Construido & Invisibilidad del Riesgo & Planificar con y para el riesgo \\
\hline Reconstrucción Sicológica & Sistema individual y unitarío & $\begin{array}{l}\text { Fortalecimiento comunitarío } \\
\text { y social }\end{array}$ \\
\hline Gestión del Riesgo & Reacción frente a la amenaza & Educación y Prevención \\
\hline Sistema Económico & Sistema mono funcional & Sistema multifuncional \\
\hline Estructura Política & $\begin{array}{l}\text { Fuerte Rol del Estado sobre } \\
\text { los gobiernos regionales y y } \\
\text { locales }\end{array}$ & $\begin{array}{l}\text { Descentralización económica } \\
\text { y política }\end{array}$ \\
\hline Capital Social & Participación Consultiva & Participación Vinculante \\
\hline
\end{tabular}

Fuente. Elaboración propia a partir de entrevistas a gestores públicos, privados y comunidad.

Asemejando las dimensiones y variables presentadas en el Cuadro $\mathrm{N}^{\circ} 4$ para el caso de Constitución se concluye, que el proceso fue liderado por una intrincada red de cooperación público-privada siendo el Gobierno Central el agente clave del proceso. La reconstrucción versó en un modelo de regulación centralizada que vinculó a la empresa CelcoArauco con algunos órganos del Estado, como el Servicio de Vivienda y Urbanismo, la oficina de reconstrucción del Ministerio de Vivienda, el Ministerio de Obras Públicas, así como también otros agentes privados como inmobiliarias, constructoras, empresas sanitarias y agencias de comunicación que aseguraban una participación ciudadana la que efectivamente no fue vinculante, salvo excepciones como aquellos pescadores que se resistieron al hábitat y que luego de tres años lograron ser radicados o relocalizados en el borde río Maule siendo conscientes de los riesgos y de las oportunidades de vivir frente al río. El gobierno central determinó la distribución de fondos en el marco de la reconstrucción, promoviendo así disparidades en las modalidades de relocalización. La regulación centralizada y liderada desde la ciudad de Santiago debilitó el poder de acción del gobierno local y dificultó los vínculos entre otros espacios intermedios y menores al interíor de la Región del Maule. Asimismo, las comunidades fueron vistas como objetos de la reconstrucción y no como sujetos claves del proceso. A la fecha no existen planes reguladores actualizados en ambas comunas lo que devela el potencial de transformación de los sitios disponibles.

A objeto de calificar las acciones de los actores claves del proceso en el Cuadro $\mathrm{N}^{\circ}$ 5 se resumen las principales calificaciones asignadas a las dimensiones del desastre (Cuadro $\mathrm{N}^{\circ} 1$ y $\mathrm{N}^{\circ}$ 4). Conjuntamente, la Figura $\mathrm{N}^{\circ} 9$ resume las ponderaciones asignadas a los agentes aquí estudiados evidenciando los cambios necesaríos para avanzar hacia una gobernanza resiliente. 

MENORES E INTERMEDIAS CHILENAS AFECTADAS POR EL TERREMOTO Y TSUNAMI DEL $27 F 2010$.

LOS CASOS DE CONSTITUCIÓN Y DICHATO

Cuadro $\mathrm{N}^{\circ} 5$

Calificación de las acciones públicas y privadas en la fase de emergencia y en el proceso de reconstrucción resiliente

\begin{tabular}{|c|c|c|c|c|c|}
\hline \multirow{2}{*}{$\begin{array}{l}\text { Dimensiones } \\
\text { Analizadas }\end{array}$} & \multirow[b]{2}{*}{ Variables Calificadas } & \multicolumn{2}{|c|}{ Constitución } & \multicolumn{2}{|c|}{ Dichato } \\
\hline & & $\begin{array}{c}\text { Rol } \\
\text { Público }\end{array}$ & $\begin{array}{c}\text { Rol } \\
\text { Privado }\end{array}$ & $\begin{array}{c}\text { Rol } \\
\text { Público }\end{array}$ & $\begin{array}{c}\text { Rol } \\
\text { Privado }\end{array}$ \\
\hline \multirow{8}{*}{$\begin{array}{l}\text { Reconstruc- } \\
\text { ción del me- } \\
\text { dio construi- } \\
\text { do }\end{array}$} & $\begin{array}{l}\text { Viviendas relocalizadas fueras de zonas de } \\
\text { riesgos }\end{array}$ & 7 & 6 & 6 & 5 \\
\hline & $\begin{array}{l}\text { Viviendas en sitio propio con medidas de } \\
\text { mitigación }\end{array}$ & 7 & 4 & 7 & 7 \\
\hline & Red secundaria infraestructura sanitaria & 7 & 6 & 5 & 5 \\
\hline & Vías secundarias & 7 & 6 & 4 & 3 \\
\hline & $\begin{array}{l}\text { Localización de centrales de telecomunica- } \\
\text { cion en zonas seguras }\end{array}$ & 6 & 5 & 6 & 6 \\
\hline & Espacios públicos en zonas seguras & 4 & 4 & 7 & 5 \\
\hline & Equipamientos en zonas seguras & 4 & 3 & 7 & 2 \\
\hline & Parque de mitigación & 4 & 4 & 4 & 1 \\
\hline $\begin{array}{l}\text { Reconstruc- } \\
\text { ción sicoló- } \\
\text { gica }\end{array}$ & Proceso psicosocial postrauma & 1 & 1 & 3 & 1 \\
\hline \multirow{2}{*}{$\begin{array}{l}\text { Gestión del } \\
\text { riesgo }\end{array}$} & Educación del riesgo & 6 & 3 & 5 & 4 \\
\hline & Modificación del plan regulador & 5 & 3 & 6 & 6 \\
\hline \multirow{2}{*}{$\begin{array}{l}\text { Sistema eco- } \\
\text { nómico }\end{array}$} & Nuevas ofertas laborales & 3 & 4 & 6 & 6 \\
\hline & Subsidios de apoyo al comercio local & 1 & 3 & 6 & 6 \\
\hline \multirow{4}{*}{$\begin{array}{l}\text { Estructura } \\
\text { política }\end{array}$} & Articulación público-privado & 5 & 3 & 3 & 3 \\
\hline & Descentralización del poder nacional & 3 & 0 & 6 & 0 \\
\hline & Articulación nivel nacional-regional-local & 3 & 2 & 5 & 1 \\
\hline & Rol del actor privado & 0 & 3 & 3 & 3 \\
\hline \multirow{2}{*}{$\begin{array}{l}\text { Capital so- } \\
\text { cial }\end{array}$} & Nuevas organizaciones sociales & 3 & 3 & 5 & 5 \\
\hline & Participacion vinculante & 3 & 3 & 4 & 2 \\
\hline \multicolumn{2}{|c|}{ Calificación asignada a cada variable por los entrevistados } & 4,2 & 3,5 & 5,2 & 3,7 \\
\hline
\end{tabular}

Fuente: Elaboración propia a partir de entrevistas en profundidad. 
Figura $N^{\circ} 9$

Estrategias de Gobernanza Resiliente en función de las dimensiones del desastre (antes y en la fase actual de reconstrucción en Dichato y Constitución)

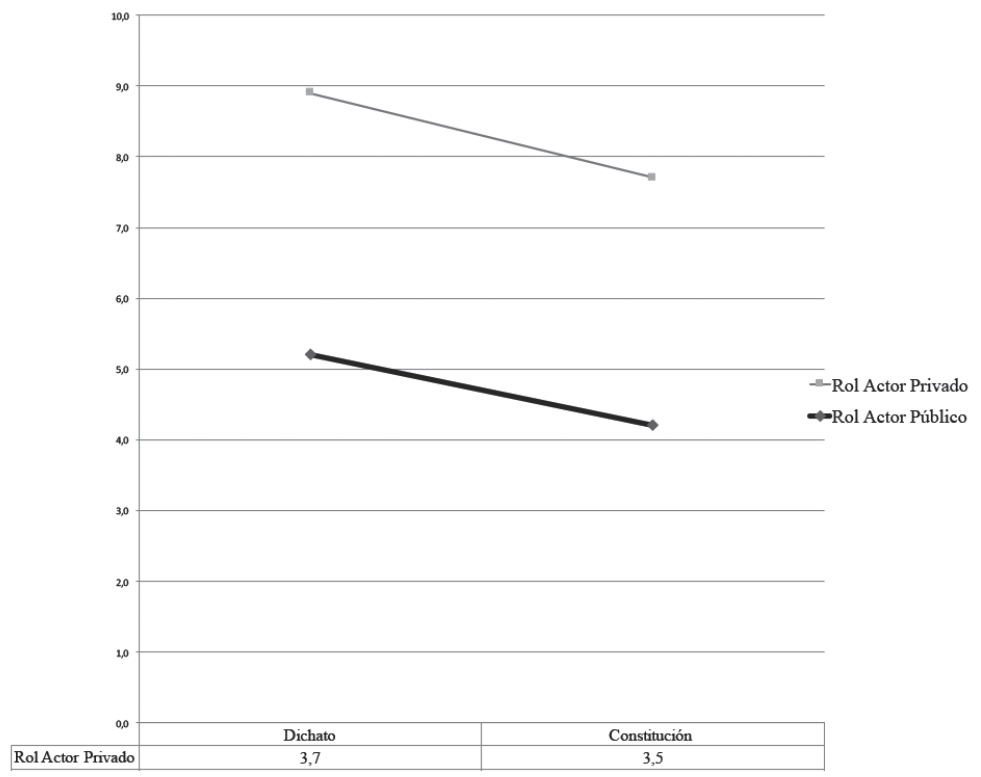

Fuente: Elaboración propia a partir de entrevistas en profundidad.

Los entrevistados, ya sean residentes como agentes públicos y privados califican la reconstrucción con una nota 4,2 en el caso de Constitución y 5,2 en Dichato. En el primer caso, una menor calificación del proceso radica en la regulación del espacio mediatizada por un Plan maestro denominado "Plan de Reconstrucción Sustentable (PRES)" que además de ser de carácter instrumental e indicativo, no establece acciones y gestiones concretas respecto a quienes podrían desarrollar los casi 37 proyectos propuestos. A la fecha se han materializado acciones y proyectos aislados fuertemente dependientes de los vínculos del gobierno central con empresas e industrias de la región y la ciudad. EI PRES emerge como iniciativa privada -en este caso el actor principal es CELCO-Arauco- frente a la invisibilización de las acciones del gobierno local de turno:

"Es algo que va a permitir que se reconstruya mejor de lo que era, porque va a dejar un legado más allá de las típicas cosas que dan las empresas, las ambulancias. Es un regalo potente. Entonces como ayudar a la ciudad: donándole un Plan Maestro".
La capitalización del desastre de la empresa privada refleja una estructura política centralista y empresarialista. De los actores públicos más representativos durante la fase de reconstrucción, el Servicio de Vivienda y Urbanismo (SERVIU) se configuró como uno de los actores más reconocidos por la comunidad, en tanto otorgaron subsidios y beneficios que permitieron el acceso a la vivienda a diferentes damnificados. Durante la fase de emergencia CELCO-Arauco identificó un equipo técnico, altamente reconocido en Chile y representado por la consultora en arquitectura Elemental, la firma internacional de ingenieros ARUP, y la empresa de gestión comunicacional liderada por Tironi y asociados, entre otros. La iniciativa partió desde el sector privado y, posteríor a eso, se incluyó al sector público a objeto de darle viabilidad y financiamiento a las iniciativas. Incluso, la Oficina Nacional de Emergencia (ONEMI) operó desde el gobierno central, en tanto desde la Región del Maule no existían las herramientas técnicas que facilitaran el proceso de reconstrucción al menos durante los dos primeros años. Conjuntamente, el desastre develó que las instituciones responsables en 
las fases de emergencia operaban en horaríos hábiles y en días administrativos, condiciones que a la fecha han sido mejoradas en cuanto a estrategias y mecanismos de comunicación que operen durante todo el año.

Posteríor al desastre, en Constitución quedaron sitios disponibles, especialmente en las esquinas de la planta urbana. La propuesta inicial del Parque de Mitigación genera expectativas de especulación, en tanto la normativa urbana actualmente se está transformando y no queda claro cuáles son sus objetivos y en qué medida logrará articular los intereses públicos, comunitaríos y privados sobre el área del desastre (Cuadro $N^{\circ} 5$ y Figura $N^{\circ}$ 9). En el caso de Dichato durante la fase de emergencia y luego del $27 \mathrm{~F}$ se conformó un equipo de urbanistas a cargo del desarrollo de los Planes Maestros para el Borde Costero (PRBC-18) que incluyó las 18 localidades afectadas por el desastre. En primer lugar se definió la capacidad de la estructura urbana de cada una de las localidades costeras para afrontar un evento en un horizonte aproximado de 30 años, de manera de generar estrategias de reconstrucción resilientes. Estas acciones explican por qué Dichato tiene un agente público calificado con nota 5,2 en desmedro del agente privado $(3,7)$ (Figura $N^{\circ} 9$ y Cuadro $N^{\circ} 5$ ). La acción del gobierno regional estuvo respaldada desde el gobierno central, en desmedro del poder de decisión de la comuna de Tomé quienes han visto mermado su poder de planificación en un contexto de reconstrucción liderado desde las estructuras regionales.

El desarrollo de un instrumento normativo que reúne a las 18 localidades más afectadas implicó la recopilación de antecedentes de experiencias de reconstrucción internacional, analizando la forma de abordar eventos con acciones coordinadas entre los gobiernos locales, regionales, estatales. El equipo tuvo que definir variables y conceptos en cuanto a las estrategias necesarias para planificar estas localidades afectadas por el terremoto y tsunami. Una de las dificultades tanto en Constitución como en Dichato fue la inexistencia de catastros y registros de propiedades, las características de los hogares, el número de personas desaparecidas, entre otros datos necesaríos a la hora de enfrentar una planificación territorial resiliente. Por otro lado, tampoco existía a nivel central ni regional ni menos local, las orientaciones específicas para la coordinación entre instituciones estatales en pos de ir en ayuda a la comunidad afectada, situación que limitaba la capacidad de desarrollar un procedimiento de planificación sustentable y resiliente. Incluso, algunas ciudades intermedias y localidades no tenían planes reguladores y cotas de inundación que permitieran redefinir las acciones de planificación. Este equipo elaboró y coordinó la primera fase de la elaboración de los planes maestros cuya ejecución y consolidación posteríormente pasó a las carteras sectoriales, así las viviendas quedaron en manos del SERVIU, las obras urbanas y de mitigación a cargo del Ministerío de Obras Públicas (MOP) y las aprobaciones y factibilidades de los proyectos a cargo del Ministerío de Desarrollo Social. En este proceso, el gobierno local representado por la municipalidad solo se vinculó a través de la consolidación de los catastros y demandas sociales, pero careciendo de una real participación en la toma de decisiones, debilitándose y fracturándose la institucionalidad.

El proceso de reconstrucción en Constitución ha sido fuertemente criticado no tan solo por su naturaleza, también por las condiciones que muchos de los planes maestros implican en términos de factibilidad, temporalidad, recursos económicos, gestión de los recursos, y acción comunitaria. Uno de los déficit más importantes en el actual modelo de reconstrucción es la ausencia de un plan de largo plazo, multisectorial y descentralizado que contemple financiamientos específicos y una institucionalidad a través de la cual se implemente (Poduje, 2011; Rodríguez, 2013).

En la Figura $N^{\circ} 9$ se hace explícito que la escasa articulación entre agentes públicos y privados dificulta las posibilidades de lograr una gobernanza resiliente que significa planificar con y para el riesgo; fortalecer las bases comunitarias en diferentes temporalidades (corto, mediano y largo plazo); prevenir y ejecutar acciones de educación del riesgo y del trauma postdesastre; así como también, descentralizar económica y políticamente las decisiones de los agentes locales y regionales. A lo anteríor se suma la necesidad de una participación vinculante y no consultiva 
que responda a una planificación territorial pensada desde el riesgo y no desde la normalidad.

En el caso de Dichato la conducción pública, regional y autónoma garantizó la validación de los Planes Maestros y las inversiones necesarias en las respectivas carteras ministeriales, aunque aún no se actualiza el Plan Regulador Comunal de la comuna de Tomé dentro de la cual se encuentra la localidad de Dichato. En un inicio se evitó la dispersión sectorial, el debilitamiento del aparataje público en pos de la inversión privada. Cumplida la etapa anteríor cada una de las carteras sectoriales no tuvo capacidad de coordinación ni de visión a largo plazo. Irazábal et al. (2015) indican que "luego de cuatro años de reconstrucción (2014), las principales obras están asociadas a iniciativas sectoriales del Ministerío de Obras Públicas (DOP, DOH y Dirección de Vialidad) con caminos y puentes; y al Ministerío de Vivienda y Urbanismo con la construcción mediante subsidios a la demanda o en forma directa de viviendas, vialidad intermedia, espacios públicos, pavimentación y parques urbanos (mitigación)" (p. 138).

Este modelo de reconstrucción tiene una serie de efectos sobre el territorío que no necesariamente se condicen con las realidades que se vivían en las localidades previamente al terremoto y tsunami (Figura №5) y aún más, en circunstancias específicas podrían significar un nuevo shock para las personas lo que en palabras de Letelier y Boyco (2011) se expresa en que "el modelo no se hace cargo de los efectos que el terremoto, y en particular el mercado de la reconstrucción, tendrán en la pérdida de calidad urbana en nuestras ciudades y pueblos. Por último, tampoco se asume como relevante la participación de los ciudadanos en la definición de las soluciones y los horizontes de futuro posterremoto" ( $p$. 40). Bajo este escenarío se podría postular la existencia de un segundo desastre dada las incertezas en términos de regulación sobre sitios abandonados, en deteríoro, especialmente los más próximos al borde costero y borde río.

\section{Conclusiones}

Desde el análisis de ciudades intermedias y localidades menores chilenas afectadas por el terremoto y tsunami de 2010 se buscó responder cuál es la capacidad de articulación entre agentes públicos, privados y la comunidad para abordar la planificación postdesastre. Conjuntamente se cuestionó en qué medida un urbanismo pro empresarial dificulta las posibilidades de negociación entre actores, y limita el poder de negociación de las familias más afectadas. La investigación deja en evidencia que frente a desastres es urgente una acción articulada considerando que gran parte de los espacios chilenos están sometidos a múltiples riesgos, asumiendo la necesidad de una regulación que observe el borde costero de manera transversal y que asegure la toma de decisiones desde los sitios afectados y no desde el centralismo de Santiago.

Las lecciones de Dichato y Constitución si bien representan escalas espaciales diferenciadas, advierten formas no sustentables de conducción de la reconstrucción desde la dimensión política en espacios intermedios y menores. La capacidad de reconstrucción está directamente relacionada con el poder de la comunidad en tanto sujetos resilientes que tuvieron la necesidad de articular sus prácticas espaciales y sus vínculos laborales con el espacio más allá del apoyo entregado por el Estado. Estas acciones son evidentes durante la fase de emergencia, y se van redefiniendo conforme avanza la reconstrucción y las familias quedan sometidas a un segundo desastre al momento de develar dificultades en sus prácticas espaciales, en las formas de acceso a la ciudad, y en el derecho a ser parte de la toma de decisiones. En el caso particular de Dichato, las comunidades comerciales que vivían del turismo y la pesca recibieron apoyos del Estado para la redefinición de sus trabajos, en cambio en Constitución -salvo algunas excepciones- los pescadores y hogares de ingresos medios bajos y bajos debieron recurrir a nuevos créditos para reconvertirse laboralmente. 
Las temporalidades y los mecanismos de conducción de la reconstrucción son divergentes. En Dichato el gobierno regional tuvo mayor presencia en términos de decisiones y asignación de recursos al menos durante los cuatro primeros años de ocurrido el desastre. Situación contraria sucedió en Constitución, donde la imposición del gobierno central sobre el local al menos durante los dos primeros años, hicieron confusa la temporalidad del proceso, cuestionando la posibilidad de construir el Parque de Mitigación en tanto no se hacían explícitos quiénes aportarían los recursos para su construcción y mantención. Lo anteríor no niega que a la fecha, es decir a seis años del $27 \mathrm{~F}$ se han construido obras necesarias para la comunidad en términos de ocio, pero no en función de su capital de movilidad, especialmente aquellos relocalizados fuera de la planta urbana que ven limitadas sus formas de acceso a la ciudad.

Lo que hace diferente estos dos casos es el rol del agente privado en la conducción del proceso, siendo en Constitución PresArauco el principal gestor de la reconstrucción y capitalizador del desastre. En tanto, Dichato si bien tiene una escala menor respecto a Constitución ha desarrollado una serie de proyectos de intervención en torno a su borde costero, liberando algunos sitios que a la fecha no tienen destino y se especula sobre las posibilidades de reconvertirlos exclusionariamente. Es aquí donde se pone el acento a que la gentrificación podría ser un proceso latente, en tanto existen condiciones de base en las dos ciudades que podrían materializarlo: suelo disponible en el borde costero, cambios normativos aún inconclusos, conectividad y belleza escénica, y un mercado de la reconstrucción como mecanismo de especulación y exclusión.

Los dos casos estudiados sustentan la tesis de una gentrificación latente dada la existencia de sitios bien localizados, demolidos y destruidos así como también, la construcción de parques que valorizan tanto el borde costero como el borde río. La existencia también de normativas urbanas aún no aprobadas o en procesos de discusión, también prepara el espacio para el arribo de mejores pagadores en un contexto que se sustenta en un empresarialismo urbano. Tanto en Dichato como en Constitución los roles de los gobiernos locales al menos en la fase de emergencia, sustentaron las bases para que aquellos con mayor poder de negociación ocuparan los sitios mejor localizados, o bien no fueran erradicados.

La reconstrucción desde el Estado chileno en la fase de emergencia, estuvo orientada a un derecho básico que es la vivienda. Sin embargo, la construcción de instrumentos como planes maestros (PRES) no condujeron a acciones que en el tiempo garanticen una acción pro activa, vinculante y sustentable. El tipo de edificaciones y la calidad de estas llevan a cuestionarse qué es lo resiliente de estas, especialmente en Dichato donde gran parte de las operaciones postdesastre se realizaron en la misma zona de inundación por tsunami 27F. Un urbanismo resiliente y sustentable captura el potencial de acción de las comunidades; articula las acciones entre los gobiernos locales, regionales y centrales, y asume el riesgo como proceso recursivo y dinámico. La construcción del Parque de Mitigación en Constitución, así como el parque costero y el estero en Dichato exigen un diseño sustentable que disminuya los riesgos de las familias que decidieron permanecer en los espacios de origen. Lo clave es incorporar a la comunidad no solo en las fases de emergencia, sino durante toda la fase de reconstrucción que tiene una temporalidad no menor a 15 años, tal como lo evidencian experiencias en Estados Unidos o en Japón.

Lo sustentable de la planificación postdesastre también está asociada a la existencia de un Estado que sea garante de la generación de espacios residenciales donde las familias tengan aseguradas formas de acceso a la ciudad. Asimismo, se requieren cambios normativos que incorporen el diseño sustentable que definen zonas condicionadas para el riesgo producto de la recursividad de estos en Chile.

\section{Referencias bibliográficas}

ARENAS, F.; LAGOS, M. e HIDALGO, R. Los riesgos naturales en la planificación territorial. En: CENTRO DE POLÍTICAS PÚBLICAS UC. Temas de la Agenda Pública. Santiago de Chile: Ediciones UC, 2010, Año 5, No 39. Disponible en Internet: http://politicas- 
publicas.uc.cl/wp-content/uploads/2015/02/ los-riesgos-naturales-en-la-planificacionterritorial.pdf

BELLET, C. y LLOP, J.M. Miradas a otros espacios urbanos: Las ciudades intermedias. Scripta Nova. Revista de Geografía y Ciencias Sociales, 2004, Vol. VIII, No 165. Disponible en Internet: http://www.ub.es/geocrit/sn/sn165.htm

BORSDORF, A. El desarrollo urbano de Valdivia. Estudio de caso en una ciudad mediana. Espacio y desarrollo, 2004, № 12. Disponible en Internet: http://revistas.pucp. edu.pe/index.php/espacioydesarrollo/article/ view/8089/8384

BRENNER, N.; PECK, J. \& THEODORE, $\mathrm{N}$. Variegated neoliberalization: geographies, modalities, pathways. Global Networks, 2010a, Vol. 10, № 2, p. 182-222.

BRESCIANI LECANNELIER, L. Chile 27F 2010 La catástrofe de la falta de planificación. EURE, 2010, Vol. XXXVI, No 108, p. 151-153.

CONTRERAS, Y. y BELTRÁN, M. Reconstruir con capacidad de resiliencia: El casco histórico de la ciudad de Constitución y el sitio del desastre del terremoto y tsunami del 27 de Febrero 2010. Revista INVI, 2015, № 83, p.79-115.

COMERÍO, M. Disaster Recovery and Community Renewal: Housing Approaches. Cityscape: A Journal of Policy Development and Research, 2014, Vol.16, p.51-68.

CUTTER, S.; BARNES, L.; BERRY, M.; BURTON, C.; EVANS, E.; TATE, E. \& WEBB, J. A place-based model for understanding community resilience to natural disasters. Global Environmental Change. Sciencie Direct, 2008, No 18, p.598-606.

DIRECCIÓN DE OBRAS HIDRÁULICAS. Estudio de Factibilidad y diseño definitivo Mejoramiento Estero Dichato. Tomé: 2010.

GONZÁLEZ-MUZZIO, C. El rol del lugar y capital social en la resiliencia comunitaria posdesastre. Aproximaciones mediante un estudio de caso después del terremoto 27/F. EURE, 2013, Vol 39, Nº117, p. 25-48.

HARVEY, D. El derecho a la ciudad. Barcelona: Institut de Drets Humans de Catalunya y el Observatorío DESC, 2008.

INZULZA, J. Latino gentrificación y polarización: transformaciones socioespaciales en barríos pericentrales y periféricos de Santiago, Chile. Revista de Geografía Norte Grande, 2014, No 58, p. 135-159.

IRAZÁBAL, C. Learning from 27F: A comparative Assessment of Urban Reconstruction Processes After the 2010 Earthquake in Chile. Santiago de Chile: Columbia-Chile Fund de Columbia Global Center Santiago y CONICYT, 2015.

GONZÁLEZ MUZZIO, C. El rol del lugar y el capital social en la resiliencia comunitaria posdesastre. Aproximaciones mediante un estudio de caso después del terremoto del 27/F. EURE, Vol. 39, No 117, 2013, p. 25-48.

GROUND, H. The New Orleans that Race Built: Racism, Disaster, and Urban Spatial Relationships. Critical Journal of Black Politics, Culture, and Society, 2007, Vol. 9, № 1, p. 4-18.

KLEIN, N. La doctrina del shock. El auge del capitalismo del desastre. Buenos Aires: Paidós, 2008.

LETELIER, F. y BOYCO, P. Talca posterremoto: una ciudad en disputa. Modelo de reconstrucción, mercado inmobiliarío y ciudadanía. Santiago de Chile: Ediciones SUR, 2011.

MARCUSE, P. Gentrification, abandonment and displacement: Connections, causes and policy responses in. Journal of Urban and Contemporary Law, 1985, № 28, p. 195-240.

MITCHELL, J. Megacities and natural disasters: a comparative analysis. Geo/ournal, 1999, No 49, p.137-142.

PRBC-18. Memoria Plan Maestro de Dichato. Concepción: Gore Bio Bio, 2012. 

MENORES E INTERMEDIAS CHILENAS AFECTADAS POR EL TERREMOTO Y TSUNAMI DEL 27F2010.

PODUJE, I. Recomendaciones plan ciudad y vivienda. En: Seminarío Reconstrucción Inteligente, 2011. Disponible en Internet:

http://www.sofofa.cl/BIBLIOTECA_Archivos/ Eventos/2010/04/21_IPoduje.pdf.

QUINCENO, C. Escenaríos de una catástrofe. AIBR Revista de antropología Iberoamericana, 2013, Vol. 39, p. 1-6.

RASSE, A. y LETELIER, F. El proceso de reconstrucción de viviendas en el centro de Talca: fotografía a dos años de la catástrofe. Revista INVI, 2013, Vol. 28, № 17, p. 139-164.
RODRÍGUEZ, A. Reconstrucción: más lenta que los discursos. El Quinto Poder, 2015, Disponible en Internet: http://www. elquintopoder.cl/desarrollo-regional/reconstruccion-mas-lenta-que-los-discursos/

SABATINI, F. y BRAIN, I. La segregación, los guetos y la integración social y urbana: Mitos y Claves. EURE, 2008, Vol. XXXIV, No 103 , p. 5-26.

TIERNEY, K. Disaster Governance: Social, Political, and Economic Dimensions Annual. Environment and Resources, 2012, Vol. 37, p. 341-363. 
